\title{
MB Redox Broth Growth Medium
}

National Cancer Institute

\section{Source}

National Cancer Institute. MB Redox Broth Growth Medium. NCI Thesaurus. Code C128950.

A liquid and selective growth medium that is modified based on the Kirchner medium by the addition of a mixture of antimicrobial ag ents (typically polymyxin $B$, amphotericin $B$, carbenicillin, and trimethoprim) and colorless tetrazolium salt as a growth indicator, which is developed for the cultivation of mycobacterium. 